\title{
谷地形のある山岳モデルをすぎる安定成層流に関する実験
}

辰野 正和 ${ }^{\circ}$ (九大応力研), 中塚 志保 (全日本空輸(株)), 石井 幸治(九大応力研)

\author{
Experimental Study on the Stratified Flow \\ over a Ridge with a Valley \\ Masakazu TATSUNO, Shiho NAKATSUKA and Koji ISHI-I
}

\begin{abstract}
An experimental study has been made of the stably stratified flows over a ridge or a ridge with a valley. The experiments were performed by towing models through linearly stratified saline-water solutions. The Froude number $\mathrm{Fr}\left(=U_{0} / \mathrm{N} H\right)$ was changed from 0.1 to $1.67($ and $\infty)$, where $U_{0}$ is the towing speed, $N$ the Brunt-Väisälä frequency and $H$ the height of models. Flow structures around models were visualized by means of the electrolytic precipitation method, and the velocity fields at several vertical cross sections were determined by PIV method.

In the case of a ridge with a valley, the flow has funneled to the valley and a strong flow has been generated downwards along the slope of the valley at low values of Fr. When $\mathrm{Fr}>0.8$, however, the flow funneled to the valley could not been observed.
\end{abstract}

Key Words : Stratified flows, Mountain models, Flow visualization

1.はじめに

山岳域を越える大気の流れの研究に関しては、観測、 モデル実験、数值シミュレーション等がなされている.

坬立峰を過ぎる流れに関しては、密度成層場を作った 水槽実験としては、Brighton ${ }^{1)}$, Hunt \& Snyder ${ }^{2)}$, Boyer et al. ${ }^{3)}$ ，日野等 4)の研究、また中立流における風 洞実験としては、孟・日比等 5)の報告がある.

一方、二次元的な山岳モデルに関する研究は少ない. Castro et al. ${ }^{6)}$ は、三角形断面を持ったリッジモデルに ついて、密度成層流を作った水棤で実缽を行っている。 内田、大屋 7,8 ) 怯、有限流路内の二次元丘陵地形を過ぎ る安定成層流に関する数值シミュレーションを行ってい る. また, 石原, 日比 凤は, 中立流場における 2 次元山 をすぎる流れの数值解析を行っている.

本研究では、大気の流れに対する複雜地形の影響の一 つとして、二次元的な山岳モデル、およびその一部に谷 地形がある場合について水槽を利用したモデル実験を行 j.

\section{2. 英駼装照および方法}

使用した水棤は、幅 $40 \mathrm{~cm}$ ，樑さ $40 \mathrm{~cm}$ ，長さ $6 \mathrm{~m}$ で あり、その上部にある曳航電車にモデルを固定して走行
させる.

実験を行った作業流体は、水だけの中立流および水と 㙁水による安定な成層流体であった，種々の直線状の密 度勾配を持った成層流は、水と㙁水による二槽式密度成 層流作成装置で生成した，成層流体の密度分布は，電気 伝導度計で計測した．直線状の密度勾配を持った成層流 体中での山岳モデルまわりの流れの特性を表すパラメー ターとしては, フルード数 $\mathrm{F}=U_{0} / \mathrm{N} H, \mathrm{~K}=\mathrm{N} D / \pi U_{0}$, $\varepsilon=\pi H I D, R_{\boldsymbol{\theta}}=U_{0} H I v$ がある.ここで、U $U_{0}$ はモデル の進行速度、 $H$ はモデルの高さ、 $D$ は水梁, $v$ は動粘 性保数, $\mathrm{N}$ はフフルント・バイサラ振動数であり、 $\mathrm{N}=$ $\left(\mathrm{g} / \rho_{0} \cdot \partial \rho / \partial \mathrm{z}\right)^{1 / 2}$ で表される. $\mathrm{g}$ は重力加速度、 $\rho 0$ は平均密度、 $\partial \rho / \partial \mathrm{z}$ は高さ方向の密度勾配である。

山岳モデルとして、Fig.1 に示すように、2 個のモデ ルを作成した. 第 1 のモデルは、二次元 ridge モデルで あり、その断面は高さ $5 \mathrm{~cm}$, 底部 $17.3 \mathrm{~cm}$ の二等边三角 形をしている.つまり、両斜面の底面とのなす倾斜角は $30^{\circ}$ である. 横の長さは $39.4 \mathrm{~cm}$ であった. 第 2 のモデ ルは、基本形は第 1 のモデルと同様であるが、長さ $39.4 \mathrm{~cm}$ の中央部に幅 $5 \mathrm{~cm}$, 深さ $2.5 \mathrm{~cm}$, 両側面の傾斜 角 $45^{\circ}$ の谷が工作されている.両モデルとも材料は発 泡スチロールであるが、強度と防水効果をかねて、その 表面には接着郕と石霄の混合した物を叙布したのち、黒 色スプレーで着色している. 


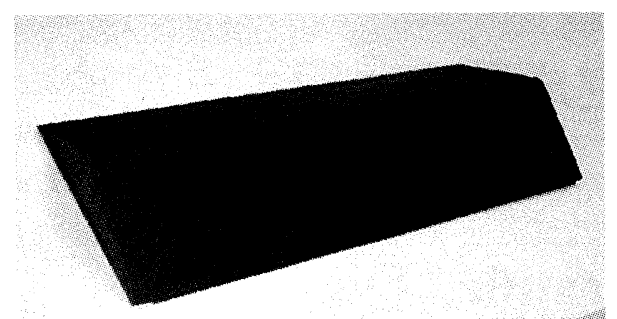

(a) A ridge model

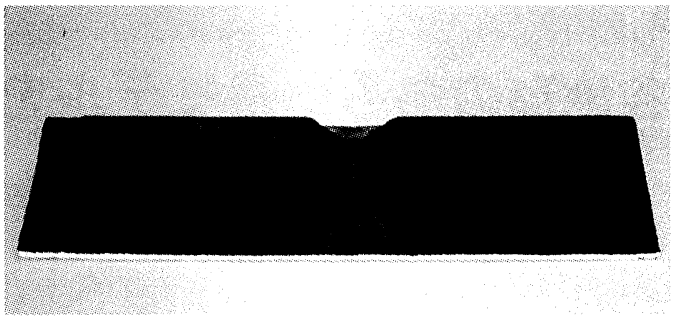

(b) A model with a valley

Fig. 1 Experimental models

流れの構造の定性的な可視化のためには、電解沈殿法 を利用した．さらに、流速分布の定量的な計測のために は、PIV 法を利用した。この際、流体には微粒子を混 入した，使用した微粒子は、ポリエチレン粒子に道当な 接着剂被膜を作り、密度の異なる流体中のどこにも微粒 子が分散して存在するようにした．ビデオカメラで掫影 した映像（1/30 秒間隔）の適当な 2 枚を選び、それら の映像間での微粒子の変位から速度場を求める. 使用し たソフトは、ライブラリー社の流体画像解析ソフト Flow-vec32 であった.

本実験では、一様流方向にX 軸、モデル軸に沿って $\mathrm{Y}$ 軸、鉛直上向きに $\mathrm{Z}$ 軸をとる. また、各点の合成平 均速度を $U 、 \mathrm{X}$ 方向平均速度成分を $U_{\mathrm{x}} 、 \mathrm{Z}$ 方向平均速 度成分を $U_{z}$ とする.

\section{3. 实跘結果}

\section{1. 二次元 ridge}

二次元 ridge を越える流れには, 安定成層の度合いに よって, blocking, lee wave, ローター, 研波, 剥離域 などの様々な現象があらわれることがわかった。

blocking 現象は, Fr 数の小さい程広領域で現れ, Fr 数の增加とともに領域は小さくなる. さらに Fr 数の小 さい强安定成屎の状態では, 山を越える流れは山の後方

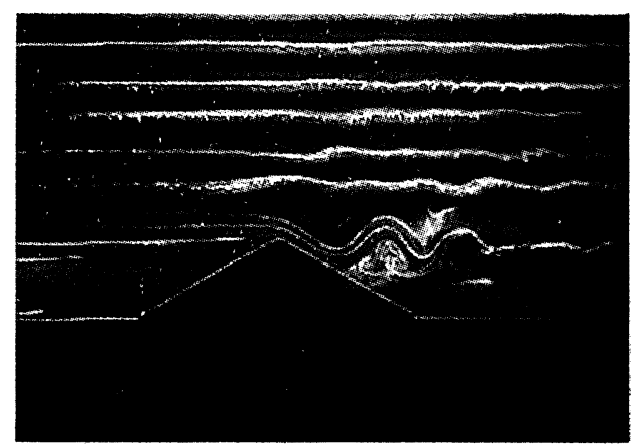

(a) A vertical plane view of the flow over the ridge
斜面を速い速度ですべり下り、斜面の途中で lee wave を形成する. Fr 数が小さい程 lee wave の波長は短く， Fr 数が大きくなるにつれ，その波長も長くなってゆく．

Fr 数が 0.4 程度になると, 山の後方萑まで流れは すべりおりるようになる.これは、いわゆるおろしの状 態であり，山の斜面に沿う流れの速度はかなり速く，山 の麓では一様流 $U_{0}$ の約 2.2 倍の速さにもなっている. また lee wave 上方にできた碎波領域では，流れはほほ 停滞していることがわかった. しかし Fr 数が 0.8 程度 以上になると，流れは山の頂上付近で剥離をおこし，山 の下流側には剥離領域が形成されるようになる。

\section{2. 谷モデル}

Fig2 に, Fr=0.11 の場合の山部, 谷部それぞれの部 分での縋断面写真を示す. 山部には下流側に lee wave ができており, 山斜面の $1 / 3$ の位置まで降りてきている. 上流側には blocking 㴭域がある. 山部の流れの縋断面 の観察は谷中央部より $9 \mathrm{~cm}$ の位置で行ったが，二次元 ridge の Fr=0.1 の場合の流れとほぼ同じであった.

谷部では, 山の高さの blocking 領域に溜まった流れ が, 収束して谷に沿って流れ出る。 その上方には lee wave らしきものものができかけている. PIV 計測によ ると, 谷を抜けた，下流側の地面付近で，流速は極端に 速くなっており，U⿺乚 $U_{0}$ の約 6 倍もの速さになってい る.こうした谷への収束流は，Fr 数が小さいほと影著

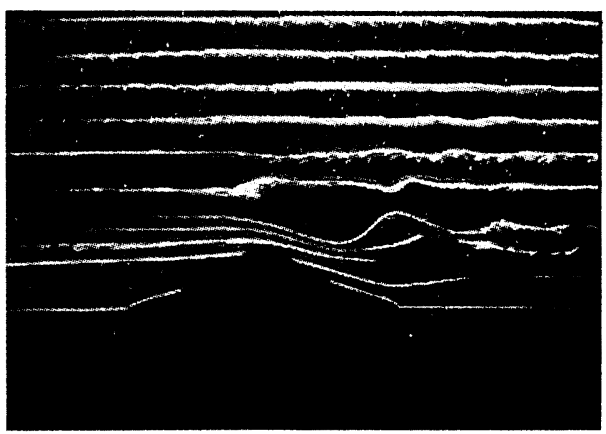

(b) A vertical plane view of the flow over the valley

Fig. 2 Flow over the model at $\mathrm{Fr}=0.11$.

$U_{0}=0.44 \mathrm{~cm} / \mathrm{s}, \mathrm{K}=14.85, \varepsilon=0.628, \mathrm{R}_{\theta}=193$ 


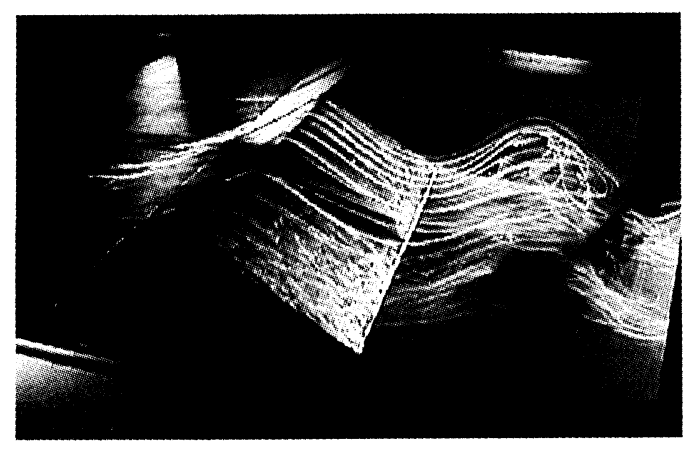

(a) A bird's-eye view of the flow over the model

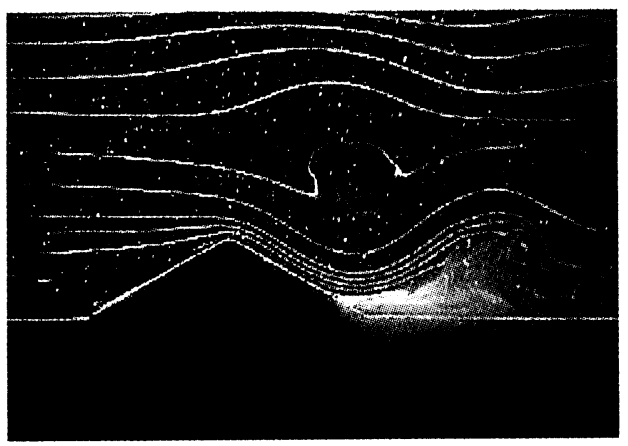

(c) A vertical plane view of the flow over the ridge

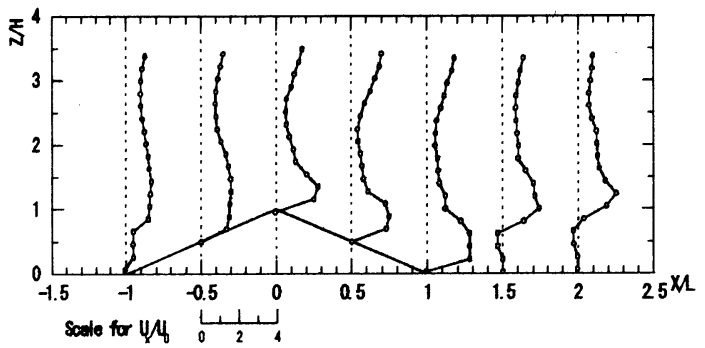

(e) Distributions of $U_{\mathrm{x}} / U_{0}$ in a vertical cross section over the ridge

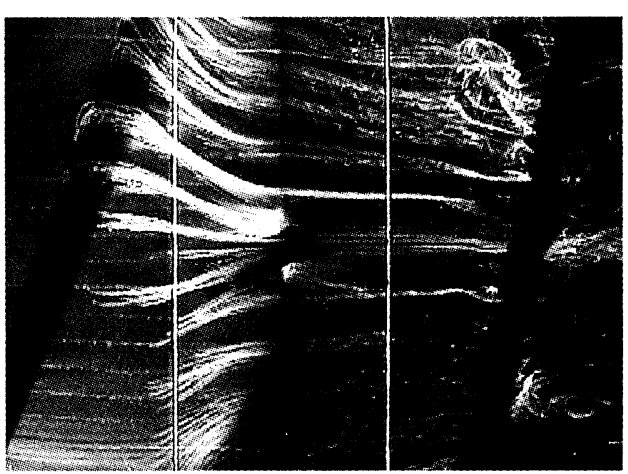

(b) A top view of the flow over the model

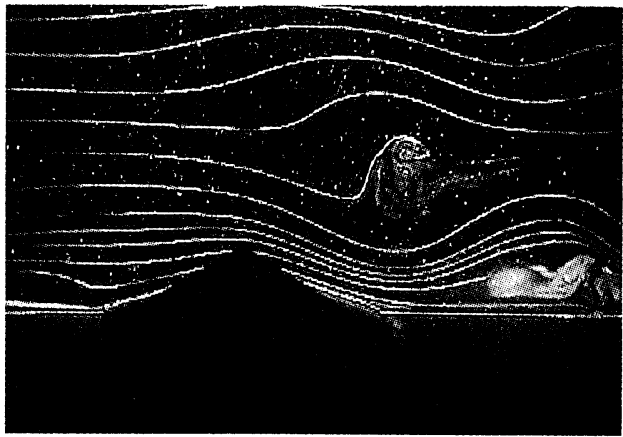

(d) A vertical plane view of the flow over the valley

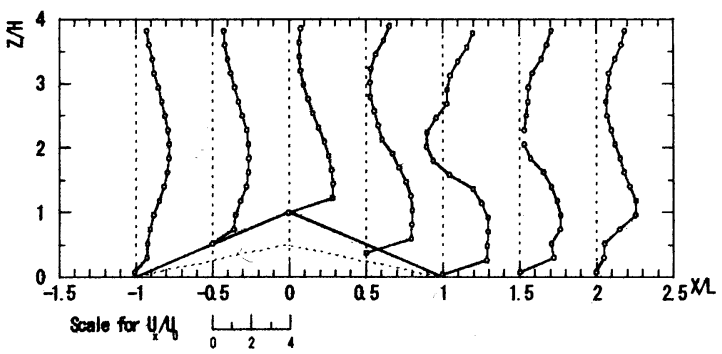

(f) Distributions of $U_{\mathrm{x}} / U_{0}$ in a vertical cross section over the valley

Fig.3 Flow over the model at $\mathrm{Fr}=0.43$.

$U_{0}=1.0 \mathrm{~cm} / \mathrm{s}, \mathrm{K}=3.73, \varepsilon=0.628, R_{\theta}=422$.

である.

Fig3 に, Fr=0.43 の場合についてモデルまわりの流 れの鳥瞰図，水平な断面を上から見た様子（Top view）， 山部・谷部の縦断面写真および PIV 法により求めた山 部, 谷部の代表的な地点の $U_{x}$ の路直分布を示す. (b)の Top view の写真で、中央部に見える繸の 2 本の白線は、 モデルの裾を表している。まず，これらの図から，モデ ルの上流側には, blocking 領域があることがわかる. しかし，その領域は，Fr=0.11 の場合より小さい.

また，山部では，Fr=0.4 の場合の二次元 ridge と同
様に, 山の斜面に沿って流れが滑り降りる，いわゆるお ろしの状態になっているのがわかる. 山を下り降りた麓 では $U_{\mathrm{x}}$ は $U_{0}$ の約 2.2 倍になっている.

一方, 谷部には, 風上側の左右から収束し, 集まって くる流れがあり，流速は增し，斜面に沿って流れ下る. 谷を流れ下った地面付近では $U_{x}$ は $U_{0}$ の約 2.4 倍とな っている.

Fr 数が 0.5 以上になると, 風上側での谷への収束流 はほとんどなくなるようである.

Fig. 4 に, Fr=0.80 の場合の, 山部, 谷部の綐断面写 


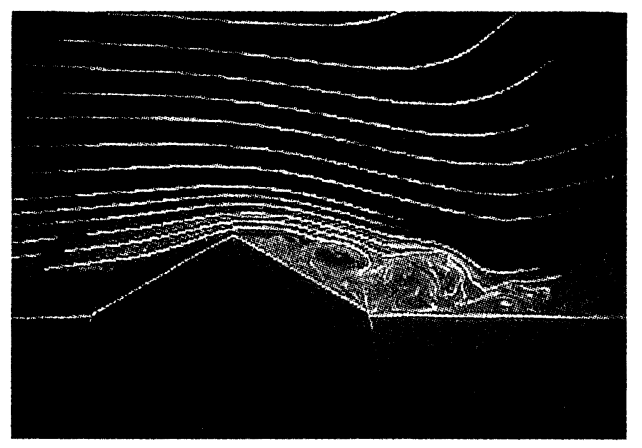

(a) A vertical plane view of the flow over the ridge

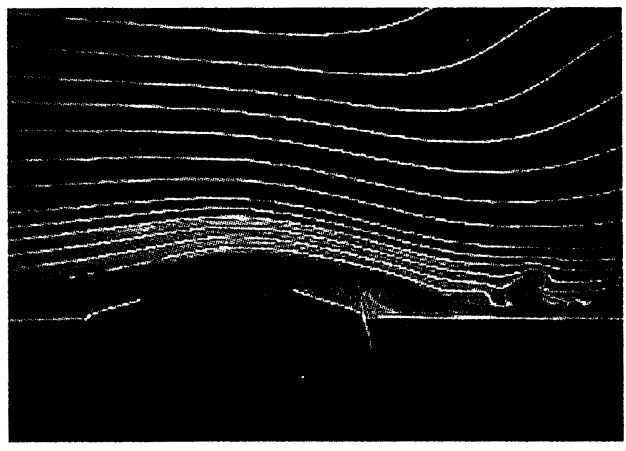

(b) A vertical plane view of the flow over the valley

Fig.4 Flow over the model at $\mathrm{Fr}=0.80$.

$U_{0}=1.88 \mathrm{~cm} / \mathrm{s}, \mathrm{K}=1.98, \varepsilon=0.628, \mathrm{Re}_{\boldsymbol{\theta}}=822$.

真を示す.ここでは，モデル上流側での blocking 領域 がほとんどなくなる，流れの大きな特街は，山部，谷部 ともに，それそれの頂上で流れが剥離していることであ る. 山部の下流側斜面には, 大きな剥䧹渦が形成されて いるのがわかる.

\section{4. 結諭}

山脈型の二次元 ridge モデルと, その中央に谷間を工 作した谷モデルをすぎる安定成層流の特性を, Fr 数を 変化させて調べた，その結果以下のことがわかった。

二次元 ridge の低 Fr 数領域では, 上流側に blocking 現象が起こる，山の下流側には，風下波(lee wave)が発 生し、lee wave の上方に注破，下方にはローターが

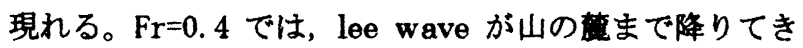
ており，いわゆるおろしの状站になっている. 二次元 ridge の高 Fr 数領域では, 流れは山頂上で剥離し, 山 の斜面に沿って渦が発生する.

谷モデルでは, Fr 数の小さな強安定状態の時に, 谷 への収束流が発生することがわかった。こうした収束流 は, Fr<0.5 で起こっている. 弱安定成層の高 Fr 数領 域では，谷間に横方向から収束する流れが入らなくなる. また山部, 谷部ともにその頂上での流れの剥礁が起こる ようになる。
1) P. W. M. Brighton : Strongly stratified flow past threedimensional obstacles, Quart. J. R. Met. Soc. 104 (1978) pp.289-307.

2) J. C. R. Hunt \& W. H. Snyder : Experiments on stable and neutrally stratified flow over a model three-dimensional hill, J. Fluid Mech. vo96, part4 (1980) pp.671·704.

3) D. L. Boyer, P. A. Davies, W. R. Holland, F. Biolley \& H. Honj : Stratified rotating flow over and around isolated three-dimensional topography , Phil. Trans. R. Soc. Lond. A322 (1983) pp.213-241.

4）日野幹雄, 日向博文, 奥村卓也：安定成思中における环 立峰周りの流九の可視化(指示省法)，可視化情報，vol.11， Suppl. No1 (1991) pp.131·134..

5）孟岩, 日比一喜：急な斜面をもつ 3 次元孤立峰周りの流 れ埸の乱流特性，日本風工学会誌，第 73 号(1997) pp.3. 14. .

6) I. P. Castro, W. H. Snyder \& G. L. Marsh : Stratified flow over three-dimensional ridges, J. Fluid Mech. vol.1135 (1983) pp.261-282.

7) 内田孝紀, 大屋 咗二：有限流路内の二次元丘陵地形を過 ぎる安定成層流の非定常性, ながれ 17 (1998) pp.45·46.

8）内田孝紀, 大屋 喛二：有限流路内の二次元丘陵地形を過 ぎる安定成層流の非定常性一第 2 報非定常な剥噰・再付着 流れに対する安定成啳の効果一，ながれ 18 (1999) pp.308. 320.

9）石原孟，日比一喜：2次元山における風の增速に閉する 数值解析, 第 16 回風工学シンポジウム $(2000) \mathrm{pp} .37 \cdot 40$. 